\title{
Configurações
}

Revista de sociologia

\section{Desafios teóricos e epistemológicos para uma análise crítica da internacionalização do ensino superior em Portugal}

Theoretical and epistemological challenges for a critical analysis of the internationalization of higher education in Portugal

Défis théoriques et épistémologiques pour une analyse critique de

l'internationalisation de l'enseignement supérieur au Portugal

\section{Eunice Seixas}

\section{OpenEdition}

\section{Journals}

Edição electrónica

URL: http://journals.openedition.org/configuracoes/2154

DOI: $10.4000 /$ configuracoes. 2154

ISSN: 2182-7419

\section{Editora}

Centro de Investigação em Ciências Sociais

Edição impressa

Data de publição: 1 Dezembro 2013

Paginação: 183-197

ISBN: 1646-5075

ISSN: $1646-5075$

\section{Refêrencia eletrónica}

Eunice Seixas, «Desafios teóricos e epistemológicos para uma análise crítica da internacionalização do ensino superior em Portugal ", Configurações [Online], 12 | 2013, posto online no dia 19 novembro 2014, consultado o 21 abril 2019. URL : http://journals.openedition.org/configuracoes/2154 ; DOI : $10.4000 /$ configuracoes. 2154 


\title{
Desafios teóricos e epistemológicos para uma análise crítica da internacionalização do ensino superior em Portugal
}

\author{
Theoretical and epistemological challenges for a critical analysis of the \\ internationalization of higher education in Portugal \\ Défis théoriques et épistémologiques pour une analyse critique de \\ l'internationalisation de l'enseignement supérieur au Portugal
}

Eunice Seixas

\section{Introdução}

1 As políticas neoliberais na educação têm sido responsabilizadas por colocar em causa a missão das universidades enquanto "[...] espaços potenciais de desenvolvimento do pensamento crítico e de formas de conhecimento orientadas para o interesse público e para a promoção da cidadania activa" (Estanque \& Nunes, 2003; cf. também Santos, 2011). A internacionalização, ancorada na ideia de competitividade numa economia mundial baseada no conhecimento, é uma das forças motrizes das reformas atuais do ensino superior na Europa e está ligada a um conjunto de racionais/motivações que compreendem racionais políticos, económicos, culturais e educacionais/académicos (De Wit, 2002; Knight, 2004).

2 Vários autores têm criticado a predominância dos racionais económicos sobre os racionais educacionais e culturais na implementação das reformas educativas na Europa e alertado para os riscos associados à mercadorização do ensino superior e a um défice democrático na instituição de políticas europeias (Amaral \& Magalhães, 2004; De Wit, 2011; Knight, 2013; Santos, 2011; Veiga \& Amaral, 2012). Alguns destes autores defendem a necessidade de uma reflexão séria sobre a direção atual da internacionalização do ensino 
superior, assim como de uma análise das políticas e das práticas e sua relação com determinados valores e motivações para a internacionalização (De Wit, 2011; Knight, 2013). Parece faltar, no entanto, um quadro teórico e epistemológico crítico capaz de potenciar essa reflexão. Neste artigo sugere-se que os estudos pós-coloniais e descoloniais, bem como as perspetivas de Wodak e Fairclough (2010) sobre recontextualização no âmbito da análise crítica de discurso, podem constituir-se como quadros teóricos e epistemológicos capazes de promover novas possibilidades de reflexão crítica, pesquisa e resistência no ensino superior, nomeadamente para o caso português.

Este artigo começa por enquadrar a questão da internacionalização do ensino superior no âmbito das políticas de governação europeia e mais especificamente de uma vertente neoliberal das reformas de Bolonha, para depois se centrar mais particularmente na análise dessa questão para o caso de Portugal.

4 Sendo a internacionalização uma questão complexa que pode ser analisada a partir de várias perspetivas, opta-se neste artigo por um enfoque nos racionais/ motivações da internacionalização, cuja investigação tem revelado consequências problemáticas ao nível da qualidade do ensino superior europeu e de normas de igualdade e justiça dentro do mesmo. Em seguida, apresentam-se sucintamente os contributos das perspetivas de análise crítica de discurso e das teorias pós-coloniais e descoloniais para uma investigação crítica das recentes reformas neoliberais no ensino superior. Finalmente, sugere-se que a falta de um enquadramento teórico e epistemológico crítico frequentemente observada nos estudos sobre o ensino superior pode ser colmatada pelos contributos conjuntos de algumas perspetivas da análise crítica de discurso (baseadas sobretudo no conceito de recontextualização e no modo como este é utilizado por Fairclough e Wodak) e das perspetivas pós-coloniais e descoloniais, podendo constituir simultaneamente um impulso para uma atualização das mesmas.

\section{Neoliberalismo, governação europeia e internacionalização do ensino superior}

$\mathrm{Na}$ era do capitalismo do conhecimento, podemos esperar que os governos ocidentais procurem libertar-se da responsabilidade de prestação pública da educação enquanto iniciam simultânea e comprometidamente um processo de privatização dos meios de produção de conhecimento e experimentam novos modos de desenho e de promoção de uma interface permeável entre empresas de conhecimento e educação pública a todos os níveis. (Olssen \& Peters, 2005: 339-340; tradução livre da autora)

5 Nas décadas de 1980 e 1990 a ascendência do neoliberalismo nas políticas do ensino superior e do discurso associado do New Public Management, ou gerencialismo, introduziu um novo modo de regulação ou forma de governamentalidade sustentada em premissas que constituem, em grande medida, um reavivar do liberalismo económico clássico (Olssen \& Peters, 2005). Contudo, no neoliberalismo, ao contrário do liberalismo económico clássico, o Estado tem um papel importante no desenvolvimento de técnicas de auditoria, responsabilização e gestão que visam construir os objetivos e valores neoliberais de liberdade, escolha, soberania do consumidor, competição e iniciativa, assim como de conformidade e obediência a que se devem sujeitar as novas subjetividades do indivíduo "empreendedor" e competitivo (ibid:: 315). Nesta nova forma de governamentalidade, a ênfase é colocada numa pressão institucional para a 
performatividade e para os outputs mensuráveis, nomeadamente através do planeamento estratégico, dos indicadores de desempenho ou das auditorias académicas (ibid.).

Ao nível da União Europeia, a vertente neoliberal do processo de Bolonha tem contribuído para retirar responsabilidade social ao Estado, convertendo a educação num bem privado e responsabilizando os indivíduos pela sua própria empregabilidade, ideia que passa a substituir-se às de emprego e direito ao trabalho. Simultaneamente, diluem-se os mecanismos de responsabilização da União Europeia enquanto agente promotora destas políticas (supostamente consensuais) ao mesmo tempo que se tende a culpar os próprios Estados pela não adesão às mesmas, através da utilização de mecanismos de soft law' (Amaral \& Veiga, 2012).

7 Parece haver também pouco interesse em analisar em que medida os objetivos de Bolonha foram cumpridos, nomeadamente os objetivos de convergência, de mobilidade e de empregabilidade (ibid.). De facto, no que respeita à mobilidade dos licenciados, um aspeto central da internacionalização, esta permanece limitada, correndo o risco de alimentar a emergência de uma euro-elite, uma pequena minoria privilegiada (Amaral \& Magalhães, 2004). Os riscos de Bolonha compreendem, assim, a diminuição da diversidade dentro dos sistemas de ensino superior europeu, bem como da autonomia institucional, a mercadorização do ensino superior e um défice democrático na instituição de políticas europeias (ibid.).

8 Constituindo uma das forças motrizes das reformas do ensino superior na União Europeia, a internacionalização tem sido recontextualizada e operacionalizada nos vários países da Europa. O conceito de internacionalização compreende racionais políticos, económicos, culturais e educacionais/académicos que podem por vezes entrar em tensão e contradição entre si (De Wit, 2002; Knight, 2004). O modo como estas tensões têm sido resolvidas, nomeadamente através do significado conferido a estes racionais e/ou à predominância de certos racionais sobre outros, tem tido consequências problemáticas ao nível da qualidade do ensino e da justiça e igualdade no ensino superior.

9 Assim, por exemplo, a predominância de racionais económicos da internacionalização pode associar-se aos riscos de mercadorização do ensino superior, nomeadamente com a utilização do recrutamento internacional de estudantes como forma de financiamento. É necessário, como refere Ackers (2008), uma análise dos desequilíbrios e desigualdades nos fluxos migratórios intraeuropeus, ou da tensão não resolvida com a estratégia da União Europeia em promover simultaneamente o crescimento equilibrado e a coesão e a mobilidade. Estes desequilíbrios e desigualdades estão bem patentes, por exemplo, numa análise cartográfica dessa mobilidade ou no carácter não voluntário da mesma - o facto de muitos dos investigadores serem atualmente forçados a procurarem emprego ou desenvolverem a sua carreira noutros países e nos constrangimentos familiares que essa migração forçada coloca. A mobilidade não deve ser um valor em si mesmo ou um sinónimo de excelência, uma vez que se trata de um conceito multifacetado, podendo estar associado a uma necessidade e/ou a um constrangimento (ibid.).

Por outro lado, os racionais culturais têm sido relacionados com uma preocupação com a diversidade doméstica, o desenvolvimento de um currículo que promova 'competências interculturais' e um espaço de aprendizagem transnacional e inclusivo (Bourn, 2011; Dunne, 2011). No entanto, há uma grande ambiguidade conceptual a este nível (Dunne, 2011), e assume-se que a mera existência de espaços educacionais em que circulam diferentes linguagens e diferentes valores é sinónimo de interculturalidade (Leask \& 
Carroll, 2011). Os desafios colocados por estes racionais da internacionalização1 e pelos novos fluxos e espaços educacionais e 'multiculturais' (em que circulam diferentes valores e diferentes linguagens) que lhe estão associados estão ainda, na generalidade, por analisar de um ponto de vista crítico. É necessário investigar, por exemplo, em que medida é que as ideias de multiculturalidade não estão, ao nível da internacionalização do ensino superior, a ser canibalizadas pelo 'multiculturalismo neoliberal' que legitima as desigualdades e exclusões sociais e raciais, segundo uma ideologia conservadora assente num discurso individualista e meritocrático que culpabiliza a vítima e impede quaisquer ações coletivas de contestação e mudança social (Darder, 2012).

\section{Questionar a internacionalização do ensino superior em Portugal}

11 Em Portugal a maioria dos estudos tem analisado a internacionalização como um entre vários aspetos da implementação das reformas de Bolonha, sendo raras as investigações (uma exceção é o estudo de Veiga, Rosa \& Amaral, 2006) que se debruçam mais especificamente sobre esta questão e sobre a forma como os diferentes racionais da internacionalização são recontextualizados pelo Estado português e pelas diferentes instituições de ensino superior portuguesas.

Efetivamente, estes racionais não são mutuamente exclusivos e variam em importância, conforme o país, a região e a instituição (De Witt, 2011; Knight, 2004, 2013). Se, por exemplo, a União Europeia tende a associar a internacionalização às ideias de mobilidade dos investigadores e de excelência da investigação (Ackers, 2008), as instituições de ensino superior portuguesas preferem dar mais importância a uma forma de 'internacionalização em casa' e à mudança de um paradigma de ensino para um paradigma de aprendizagem, sendo a internacionalização recontextualizada pelos líderes das instituições como relacionando-se exclusivamente com questões de financiamento nacional (Veiga \& Amaral, 2009). E se a narrativa de gerencialismo ou New Public Management no ensino superior tem inspirado mudanças na legislação portuguesa e os próprios discursos das 'partes interessadas', encontramos também resistências e reformulações desta narrativa (Magalhães \& Amaral, 2007; Magalhães et al., 2013).

Num dos poucos estudos sobre a internacionalização do ensino superior em Portugal, Veiga, Rosa e Amaral (2006) analisam seis instituições de ensino superior com o objetivo de perceber as respostas das mesmas à internacionalização e identificar os fatores que promovem ou, pelo contrário, impedem o desenvolvimento de atividades internacionais no âmbito organizacional. Relativamente aos racionais da internacionalização, estes investigadores concluem que, no caso português, predominam os racionais políticos e culturais e mais recentemente, os racionais económicos, mas estes são condicionados pela natureza dos países envolvidos nas atividades de intercâmbio. Distinguem-se assim dois 'espaços' de cooperação ao nível da internacionalização do ensino superior: por um lado, o espaço 'lusófono', dos PALOP, e, por outro, a cooperação com outras regiões, com particular ênfase na Europa (ibid.: 110-111). Na cooperação com os PALOP e apenas nas instituições públicas, predominam os racionais políticos e culturais relacionados com a ideia de 'Lusofonia'. As instituições privadas dão mais relevância aos racionais económicos, tanto na cooperação com os PALOP como com a Europa. No entanto, no caso da cooperação com outros países da Europa, o significado dos racionais políticos e 
culturais muda, sendo que, por exemplo, o racional cultural está neste caso relacionado com a promoção de uma 'cidadania europeia' e o racional político liga-se à ideia de que não é possível assegurar a qualidade dos sistemas de educação nacional isoladamente do contexto internacional e em particular do europeu (ibid.: 112-113). Não sendo possível, no âmbito deste artigo, dar conta dos vários resultados interessantes deste estudo, é importante salientar o modo como o mesmo contribui para evidenciar a complexidade da recontextualização da internacionalização do ensino superior em Portugal e a importância de uma análise situada deste processo.

Em suma, as forças motrizes das reformas do ensino superior na União Europeia envolvem aspetos políticos, económicos e culturais que são recontextualizados, quer ao nível das políticas nacionais, quer ao nível das estratégias e discursos das instituições de ensino superior. Argumenta-se aqui que o conceito de recontextualização abre espaço para uma análise da complexidade dos processos sociais e dinâmicas de poder ao longo das várias escalas e relações entre as mesmas, assim como entre diferentes contextos histórico-culturais. Este conceito de recontextualização tem-se constituído como fulcral para algumas perspetivas recentes de análise crítica de discurso que se têm centrado também na análise da governação europeia na área da educação, como veremos em seguida (cf. infra secção 4).

Por outro lado, parece faltar muitas vezes aos estudos sobre a implementação das políticas educativas europeias um quadro teórico e epistemológico crítico adequado. Um olhar crítico sobre a internacionalização supõe levantar uma série de questões relacionadas com a governação europeia, as relações de poder entre os diversos países da Europa, a conceptualização da diferença, a interculturalidade, a 'cidadania europeia' ou a 'cidadania global', todas estas questões centrais às teorias pós-coloniais e descoloniais (cf. infra secção 5).

\section{Contributos da análise crítica de discurso: a recontextualização como dialética de apropriação/ colonização}

16 A análise crítica do discurso é uma orientação qualitativa para a análise de discurso, ligada às teorias sociais críticas e ao estudo das dinâmicas de poder na sociedade, ao modo como este é exercido, reproduzido e resistido, através do texto ou da fala. Na perspetiva de Fairclough e Wodak, aqui apresentada sucintamente, a análise crítica de discurso não deve debruçar-se sobre questões teóricas, mas sim sobre um problema social específico, abordando-o inicialmente sob uma perspetiva semiótica, mas que é complementada com uma análise crítica e transdisciplinar das relações dialéticas do discurso com as práticas sociais, o contexto e a materialidade. A análise crítica de discurso é considerada "[...] um recurso para a pesquisa social crítica que deve ser usado em combinação com recursos teóricos e analíticos de várias áreas da ciência social" (Fairclough, 2003: 210). E é nesta perspetiva que ganha particular relevância o conceito de recontextualização e a sua utilização para uma análise crítica da implementação das políticas educativas na União Europeia.

O conceito de recontextualização, inicialmente formulado por Bernstein (2000), relativamente ao discurso pedagógico e associado a relações de apropriação de uma prática social por outra, tem sido ele próprio recontextualizado no domínio da análise 
crítica de discurso. Com Chouliaraki e Fairclough (1999), a recontextualização passa a ser concebida como uma dialética de apropriação/ colonização cujo resultado depende de uma série de fatores contextuais. A recontextualização é entendida como a disseminação estrutural e escalar dos discursos, enquanto a operacionalização compreende a adoção de novos modos de interação (e géneros), de novos modos de ser/identidades (e estilos) e da sua materialização no mundo físico.

Por sua vez Wodak, na sua proposta de Discourse Historical Analysis (DHA), coloca a ênfase na ideia de transformação dos discursos através de contextos e na ideia de contexto como contendo vários níveis. Wodak (2011: 629-630) refere que:

As relações espaciais e temporais entre textos incluem sempre relações de recontextualização através das quais os textos (e os discursos, géneros e argumentos que estes empregam) se movem entre contextos espacialmente e temporalmente diferentes e são sujeitos a transformações cuja natureza depende das relações e diferenças entre esses contextos.

19 A recontextualização é assim um processo que envolve uma mistura de elementos textuais e discursivos 'novos' e 'velhos' (ibid.).

20 A questão da governação tem sido especificamente analisada sob o ponto de vista da recontextualização por Fairclough, que sugere que as relações de governação e metagovernação constituem uma classe particular de relações de recontextualização. Para Fairclough, os géneros e as cadeias de géneros são uma condição semiótica de qualquer forma de governação e, por isso, a análise da governação deve incluir uma análise dos géneros e não apenas dos discursos (Fairclough, 2003). No ensino superior assistimos, por exemplo, à emergência do planeamento estratégico que em si mesmo pode ser visto como um género complexo que inclui vários subgéneros (nomeadamente, a declaração da missão da organização ou as tabelas dos indicadores de desempenho). 0 discurso de mercadorização é inculcado em novas identidades, como as dos gestores das universidades, e esta mudança afeta também as identidades dos professores e dos alunos. Fairclough salienta, contudo, que este processo de mudança social não é de todo simples e que as identidades e os estilos no ensino superior contemporâneo são "híbridos, contraditórios e, por vezes, profundamente problemáticos" (Fairclough, 2007: 136). Efetivamente, se a perspetiva oficial da implementação das políticas da União Europeia tende a subvalorizar as complexidades, tensões e contradições envolvidas no processo de recontextualização, este é todavia caracterizado por uma série de antinomias entre globalização e fragmentação, homogeneização e heterogeneização (Wodak \& Weiss, 2004, 2007 apud Wodak \& Fairclough, 2010). Assim sendo, é necessária uma teorização e análise dos processos sociais, das relações e das dinâmicas envolvidas na recontextualização para a explicação das diferenças de tempo, ritmo, grau e formas de implementação das políticas (Wodak \& Fairclough, 2010).

21 Face às enormes mudanças verificadas na área da educação nas últimas décadas, a capacidade de resistência de muitos dos membros das universidades tem enfraquecido, e muitos experienciam um sentimento de desespero que a análise crítica de discurso pode ajudar a iluminar (Fairclough, 2010: 123-124). O problema deriva, em parte, de uma polarização entre práticas tradicionais inaceitáveis e as novas práticas de promoção e mercadorização, igualmente rejeitadas. Parece, portanto, haver uma ausência de uma nova linguagem que possibilite formas de contestação e resistência a estas novas práticas de mercadorização. A análise crítica de discurso pode "[...] apontar para a necessidade de 
uma luta com vista a desenvolver essa nova linguagem como elemento-chave na construção de resistência à mercadorização [...]" (ibid.: 125).

\section{Estudos pós-coloniais e descoloniais sobre a educação}

A educação é, talvez, o mais insidioso e, em alguns aspetos, o mais enigmático dos legados colonialistas, sendo que os sistemas mais antigos passam agora, às vezes impercetivelmente, para configurações neocolonialistas. (Ashcroft, Griffi ths \& Tiffi n, 2006: 371)

Os estudos pós-coloniais compreendem um conjunto heterogéneo de perspetivas interdisciplinares críticas que, em geral, se podem considerar como visando a contestação da dominação colonial, assim como do legado do colonialismo e de novas formas de dominação colonial/imperial.

O conceito de colónia, assim como o de império, remetem atualmente para diferentes significados. Podemos, por exemplo, considerar o capitalismo como imperialismo, tendo o colonialismo e o pós-colonialismo como as suas fases (Loomba, 2005). O pós-colonialismo ganharia aqui um significado de neocolonialismo, explícito na definição de Slemon (apud Childs \& Williams, 1997: 8) do pós-colonial como "o teatro moderno das relações internacionais neocolonialistas", o que remete para a análise do capitalismo financeiro e da governação liberal global como formas de neocolonialismo. Similarmente, Spivak sugere que "vivemos hoje num mundo pós-colonial neocolonizado" (Spivak, 1990: 166).

Efetivamente, o neocolonialismo pode ser hoje considerado como o impacto dos países 'desenvolvidos' sobre os 'países em desenvolvimento', representando "em parte uma política planeada das nações desenvolvidas para manter a sua influência nos países em desenvolvimento, mas sendo também simplesmente uma continuação de práticas antigas" (Altbach, 1971/2006: 381). Esse impacto pode ser mais óbvio, como é o caso da distribuição de livros escolares estrangeiros nos países em desenvolvimento, ou mais subtil, incluindo o uso de peritos e/ ou consultores técnicos dos países centrais ou a continuação de modelos administrativos e padrões curriculares estrangeiros (ibid.).

5 A educação, enquanto tecnologia de controlo social, foi sempre de importância primordial para o colonialismo, especialmente para um modo de dominação através do consentimento, teorizado por Gramsci (1971). E é na área cultural e da educação que se observa atualmente a maior parte das práticas neocoloniais, o que faz com que a educação "permaneça um dos discursos mais poderosos dentro do complexo colonial e neocolonial" (Ashcroft, Griffi ths \& Tiffi n, 2006: 373).

Em geral, os estudos pós-coloniais têm levantado questões sobre o currículo e as práticas pedagógicas e de investigação, centrando a sua crítica no viés de eurocentrismo e américo-centrismo na produção de conhecimento e revelando as continuidades entre o período colonial e 'pós-colonial'. Nomeadamente, os autores ligados a estas perspetivas têm investigado o modo como o conhecimento científico produzido atualmente em contextos europeus e norte-americanos, assim como pela elite intelectual em países 'desenvolvidos' e 'em vias de desenvolvimento', contribui para reforçar noções coloniais de cultura, poder e diferença e como em particular as questões das diferenças culturais, étnicas e 'raciais' têm sido enquadradas no contexto educacional (Subedia \& Daza, 2008). As perspetivas pós-coloniais têm criticado as interpretações hegemónicas simplistas da diversidade e da educação multicultural que dominam a educação nos EUA e chamado a 
atenção para o modo como os professores ou investigadores imigrantes e/ou transnacionais são discriminados pelos seus pares (ibid.).

Por outro lado, os estudos pós-coloniais têm salientado também as possibilidades de resistência e contestação social no campo educacional e especialmente no campo literário. Porém, as desigualdades económicas e tecnológicas que persistem atualmente entre os vários países do centro e periferia têm contribuído também para a falta de uma descolonização genuína no campo cultural e da educação (Altbach, 1971/2006).

Mais recentemente, tem vindo a ganhar relevância o 'projeto descolonial', associado principalmente a autores provenientes da América Latina. O objetivo principal do projeto descolonial é o de construir uma 'geopolítica do conhecimento' alternativa a partir do lugar epistémico subalterno, i.e., das vivências do 'Sul Global' ou da perspetiva da 'colonialidade'. Tal substituiria uma 'egopolítica do conhecimento' ou 'filosofi a do ponto zero' da perspetiva da modernidade (Mignolo, 2003; Grosfoguel, 2008). Grosfoguel (2009), um dos principais representantes do pensamento descolonial, identifi ca três aspetos do mesmo: 1. a necessidade de um cânone de pensamento mais amplo do que o cânone ocidental; 2. a recusa dos universais abstratos ou 'localismos globalizados' e a proposta de um diálogo crítico entre diversos projetos políticos/éticos/epistémicos apontados a um mundo pluriversal; 3. a necessidade de levar em consideração as perspetivas de pensadores do Sul Global, “[...] que pensam a partir de corpos e lugares étnico-raciais/ sexuais subalternizados" (ibid.: 11).

Criticando a divisão científica moderna entre sujeito e objeto, o pensamento descolonial parte de um problema concreto e não de um mero objeto de estudo que se analisaria a partir de uma distância confortável. Esse problema é o originado pela matriz moderna da colonialidade do poder, do saber e do ser, que Maldonado-Torres define da seguinte maneira:

Enquanto a colonialidade do poder se refere à inter-relação entre formas modernas de exploração e dominação (poder), e a colonialidade do saber está ligada ao impacto da colonização nas diferentes áreas de produção de conhecimento, a colonialidade do ser faria referência primária à experiência vivida da colonização e seu impacto na linguagem. (Maldonado-Torres, 2007: 242)

O projeto descolonial é, consequentemente, uma oposição às formas de colonialidade do poder, do saber e do ser (ibid.: 261). Nesta perspetiva enquadra-se também a proposta de Boaventura de Sousa Santos para uma 'epistemologia do Sul', baseada em três premissas: 1. "que a compreensão do mundo é muito mais ampla que a compreensão ocidental do mundo"; 2. "que a diversidade do mundo é infinita"; e 3. "que não existe uma teoria geral que possa cobrir adequadamente toda esta diversidade do mundo" (ibid.: 17). Partindo destas premissas, uma epistemologia do Sul tem de estar aberta a outros quadros de leitura e conhecimento, para além do conhecimento ocidental, desconstruindo assim o pretenso universalismo do mesmo.

31 No campo da educação, a perspetiva descolonial tem-se centrado na crítica contemporânea ao eurocentrismo das universidades e do conhecimento e no modo como as universidades europeias têm suprimido o pensamento crítico sobre a história do império, da escravatura e do comércio de escravos e permanecem fechadas a outras epistemologias e formas de conhecimento. Assim, por um lado, a perspetiva descolonial continua o trabalho desenvolvido pelos estudos pós-coloniais, ao dar conta do modo como determinadas vozes alternativas foram e continuam a ser silenciadas pelos cânones da ciência ocidental. Mas a perspetiva descolonial sugere também que a crise que as 
universidades europeias e americanas vivem atualmente não deriva apenas da crise financeira e das pressões neoliberais, mas da exaustão do modelo científico da modernidade ocidental (Santos, 2011). Nesta perspetiva, é necessário não só tornar visíveis as exclusões e desigualdades do atual processo de conhecimento, mas também promover um modo de conhecimento crítico e pluriversal, baseado num diálogo intercultural entre países do centro e países da periferia (Boidin, Cohen \& Grosfoguel, 2012; Santos, 2011, 2012). Um diálogo intercultural supõe pôr em causa a premissa de que a visão 'ocidental' é a única perspetiva a ser considerada e deve incluir perspetivas globais, 'transformativas e contra-hegemónicas' apoiadas em diversas teorias sociais e educacionais radicais, tais como as propostas de Paulo Freire, Giroux e Spivak (Bourn, 2011).

\section{Desafios teóricos e epistemológicos para repensar criticamente a educação e o ensino superior em Portugal}

32 Sugere-se neste artigo que, embora vários autores se tenham posicionado criticamente relativamente à governação no ensino superior e mais especificamente sobre a governação europeia e no caso português, parece faltar um enquadramento teórico e epistemológico a muitos desses estudos. Propõe-se que as perspetivas pós-coloniais e descoloniais e a análise crítica de discurso podem, separadamente mas principalmente em conjunto, constituir-se como esse quadro teórico, epistemológico e metodológico, capaz de promover novas possibilidades de pesquisa e resistência, nomeadamente para uma análise do problema da internacionalização do ensino superior, central às políticas atuais de educação na União Europeia.

33 Efetivamente, as teorias pós-coloniais e descoloniais e a versão aqui apresentada da análise crítica de discurso, apesar da heterogeneidade interna de cada uma e das diferenças entre as mesmas, partilham determinados princípios, nomeadamente: uma perspetiva orientada para a resolução de um problema social; uma perspetiva interdisciplinar que tenha em consideração as múltiplas facetas da realidade social; uma perspetiva centrada na análise das relações de poder e da mudança social e, principalmente, numa análise historicizada e crítica das formas de colonialidade do poder, do saber e do ser (esta última talvez ainda incipiente na análise crítica de discurso). Tendem ainda a subscrever (com maior ênfase nas teorias descoloniais) uma perspetiva em relação ao posicionamento do sujeito investigador que valoriza a crítica, a reflexividade e a vigilância epistemológica do mesmo.

No entanto, as teorias pós-coloniais e descoloniais têm-se debruçado ainda relativamente pouco sobre a globalização e menos ainda sobre o modo como as reformas contemporâneas do ensino superior tendem a criar e legitimar desigualdades dentro e entre os países 'desenvolvidos' e que vão para além da construção de diferenças 'étnicas' ou 'raciais', nomeadamente entre os países do Norte e os países do Sul da Europa. Mais especificamente, a internacionalização do ensino superior levanta, entre outras questões, a do significado e consequências da mobilidade dos investigadores através da Europa, da hegemonia da língua inglesa e da constituição de espaços académicos ditos 'multiculturais' onde circulam várias linguagens e culturas. 
35 As perspetivas da análise crítica de discurso sobre a recontextualização e operacionalização dos discursos de mercadorização nas universidades europeias constituem um contributo importante para uma análise situada dos processos de implementação das políticas europeias na área do ensino superior, na medida em que salientam o modo como estes incorporam dinâmicas complexas de apropriação/ colonização e fricções entre o global e o local. No entanto, a maior parte destes estudos tem-se centrado ainda em análises de textos oficiais, faltando-lhe um lado 'etnográfico' defendido por Wodak (2002) e Fairclough (2003). E essa perspetiva 'a partir de dentro', com base numa abordagem de etnografia crítica, é também fundamental para a criação de uma 'epistemologia do Sul', proposta pelo projeto descolonial.

Por outro lado, um dos principais contributos das teorias pós-coloniais (e em comum com a análise crítica de discurso) tem sido a ideia de que as práticas discursivas e culturais são essenciais e não secundárias para a produção e manutenção das relações coloniais e neocoloniais. Para além disso, os autores pós-coloniais têm salientado a capacidade do 'subalterno' de interpretar, apropriar e resistir aos discursos dominantes, revelando as várias modalidades de agência e resistência do mesmo. No entanto, são necessárias novas estratégias analíticas para a compreensão do modo como os legados culturais e económicos do colonialismo se entrecruzam e configuram em novas relações neocoloniais, revelando as continuidades e descontinuidades entre colonialismo e póscolonialismo (Rizvia et al., 2006). De facto, alguns autores consideram que as teorias póscoloniais carecem de uma revisitação dos seus conceitos-chave (especialmente dos conceitos de hibridação, mimetismo e ambivalência) para que não se tornem em teorias 'reconciliatórias' em vez de teorias realmente críticas e anticolonialistas (cf. por exemplo, During, apud Rizvia et al., 2006). Neste sentido, entra o argumento dos estudos descoloniais de que é necessário 'descolonizar' as próprias teorias pós-coloniais e alargar o cânone de pensamento para além do cânone ocidental.

Uma análise crítica dos processos de internacionalização do ensino superior em Portugal pode basear-se num entrecruzamento entre estas propostas (pós-coloniais, descoloniais e de análise crítica de discurso) com benefícios também para a atualização das mesmas na sua abordagem da globalização e governação liberal global. Espera-se que este entrecruzamento possa gerar importantes contributos críticos e de resistência a uma forma de internacionalização hegemónica assente num darwinismo económico ou de sobrevivência dos mais aptos (Giroux, 2011, 2012), que promove uma elite que se conforma às normas e valores da mercadorização do ensino superior, ao mesmo tempo que exclui todos os outros que não aderem a essas normas e valores. Esses valores não são os de um ensino nem de uma investigação de qualidade, críticos e engajados com os interesses públicos, mas os da publicação em revistas ISI, da promoção da carreira académica individual e da competitividade, do desenvolvimento de competências de escrita e desenho de projetos de modo a maximizar a obtenção de financiamento, segundo a lógica económica do mercado, do lucro e da eficiência (ibid.). Estes são também os valores da narrativa neoliberal sobre o ensino superior - o New Public Management ou gerencialismo -, que enfatiza entre outros aspetos o financiamento baseado no mercado, o fortalecimento do papel de gestão dos reitores e dos diretores de departamento e uma orientação para os resultados, através da definição de objetivos específicos e outputs mensuráveis.

Em vez de a internacionalização do ensino superior ser um processo baseado nos valores de cooperação, parceria e benefícios mútuos, este torna-se progressivamente um processo 
caracterizado pela competição, mercadorização, interesses pessoais e promoção do estatuto (Knight, 2013). O desafio atual é que todos os atores sociais envolvidos no processo educativo possam desenvolver possibilidades de reflexão e ação para reverter este processo.

\section{BIBLIOGRAFIA}

ACKERS, Louise (2008), "Internationalisation, mobility and metrics: A new form of indirect discrimination?", Minerva, 46, 411-435.

ALTBACH, Philip G. (1971/2006), "Education and neocolonialism”, in Bill Ascroft, Gareth Griffiths \& Helen Tiffin (Eds.), The Post-Colonial Studies Reader, 2nd edition: 381-384.

AMARAL, Alberto \& MAGALHÃES, António (2004), “Epidemiology and the Bolonha Saga”, Higher Education, 48: 79-100.

AMARAL, Alberto \& MAGALHÃES, António M. (2007), "Market competition: Public good and institutional governance: Analyses of Portugal's experience", Higher Education Management and Policy, 19(1): 63-76.

AMARAL, Alberto \& VEIGA, Amélia (2012), “The European Higher Education Area: Various perspectives on the complexity of a multi-level governance system”, Educação, Sociedade \& Culturas, 36: 25-47.

ASHCROFT, Bill; GRIFFITHS, Gareth \& TIFFIN, Helen (2006), "Education: Introduction to Part Fourteen", in Bill Ascroft, Gareth Griffiths \& Helen Tiffin (Eds.), The Post-Colonial Studies Reader, 2nd edition: 371-373.

BERNSTEIN, Basil (1990), The Structuring of Pedagogic Discourse. London: Routledge.

BOIDIN, Capucine; COHEN, James \& GROSFOGUEL, Ramón (2012), “Introduction: From University to pluriversity: A decolonial approach to the present crisis of Western universities", Human Architecture: Journal of the Sociology of Self-Knowledge, 10(1): 1-6.

BOURN, Douglas (2011), “From internationalisation to global perspectives”, Higher Education Research \& Development, 30 (5): 559-571.

CHILDS, Peter \& WILLIAMS, R. J. Patrick (1997), An Introduction to Post-Colonial Theory. London: Prentice-Hall.

CHOULIARAKI, Lilie \& FAIRCLOUGH, Norman (1999), Discourse in Late Modernity. Rethinking Critical Discourse Analysis, Edinburgh: Edinburgh University Press.

DARDER, Antonia (2012), "Neoliberalism in the Academic Borderlands: An On-going Struggle for Equality and Human Rights", Educational Studies: A Journal of the American Educational Studies Association, 48 (5): 412-426.

DE WIT, Hans (2011), "Globalisation and Internationalisation of Higher Education" [introduction to online monograph]. Revista de Universidad y Sociedad del Conocimiento (RUSC), 8 (2), 241-248. UOC. [Accessed: 14/09/2013] at http://rusc.uoc.edu/ojs/index.php/rusc/article/view/v8n2dewit/v8n2-dewit-eng 
DUNNE, Ciáran (2011), "Developing an intercultural curriculum within the context of the internationalisation of higher education: terminology, typologies and power", Higher Education Research \& Development, 30 (5): 609-622.

ESTANQUE, Elísio \& NUNES, João Arriscado (2003), “Dilemas e desafi os da Universidade: Recomposição social e expectativas dos estudantes na Universidade de Coimbra", Revista Crítica de Ciências Sociais, 66: 1-39.

FAIRCLOUGH, Norman (2003), Analysing Discourse: Textual analysis for social research. London and New York: Routledge.

FAIRCLOUGH, Norman (2007), "Global capitalism and change in Higher Education: dialectics of language and practice, technology, ideology", Proceedings of the BAAL Conference 2007.

FAIRCLOUGH, Norman (2010), "Critical discourse analysis and the marketisation of public discourse: the universities", in Norman Fairclough, Critical Discourse Analysis: The Critical Study of Language. London: Longman, 2nd edition.

GRAMSCI, Antonio (1971), Selections from the Prison Notebooks. Nova Iorque: International Publishers.

GROSFOGUEL, Ramón (2008), "Para descolonizar os estudos de economia política e os estudos pós-coloniais: Transmodernidade, pensamento de fronteira e colonialidade global”, Revista Crítica de Ciências Sociais, 80 (março): 115-147.

GROSFOGUEL, Ramón (2009), “A Decolonial Approach to Political-Economy: Transmodernity, Border Thinking and Global Coloniality”, Kult 6 - Special Issue Epistemologies of Transformation: The Latin American Decolonial Option and its Ramifications: 10-38.

GIROUX, Henry (2011) “The Disappearing Intellectual in the Age of Economic Darwinism”, Policy Futures in Education 9: 163-171.

GIROUX, Henri (2012), "Higher Education, Critical Pedagogy, and the Challenge of Neoliberalism: Rethinking the Role of Academics as Public Intellectuals”, Aula de Encuentro: Revista de investigación y comunicación de experiencias educativas, 15: 15-27.

KNIGHT, Jane (2004), “Internationalization Remodeled: Defi nition, Approaches, and Rationales", Journal of Studies in International Education, 8(1): 5-31.

KNIGHT, Jane (2013), "The changing landscape of higher education internationalisation - for better or worse?", Perspectives: Policy and Practice in Higher Education: 1-7.

LEASK, Betty \& CARROLL, Jude (2011), “Moving beyond 'wishing and hoping': internationalisation and student experiences of inclusion and engagement", Higher Education Research \& Development, 30(5): 647-659.

LOOMBA, Ania (2005), Colonialism/Postcolonialism. London and New York: Routledge.

MAGALHÃES, António; VEIGA, Amélia; AMARAL, Alberto; SOUSA, Sofia \& RIBEIRO, Filipa (2013), "Governance of Governance in Higher Education: Practices and lessons drawn from the Portuguese case", Higher Education Quarterly, 67: 295-311.

MAGALHÃES, António M. \& AMARAL, Alberto (2007), “Changing values and norms in the concept of governance in Portuguese higher education", Higher Education Policy, 20: 315-338.

MALDONADO-TORRES (2007), "On the coloniality of being”, Cultural Studies, 21(2-3): 240-270.

MIGNOLO, Walter D. (2003), “Os esplendores e as misérias da 'ciência': colonialidade, geopolítica do conhecimento e pluriversalidade epistémica”, in Boaventura de Sousa Santos (org.), Conhecimento Prudente para uma Vida Decente. Porto: Edições Afrontamento: 631-672. 
OLSSEN, Mark \& PETERS, Michael A. (2005), "Neoliberalism, higher education and the knowledge economy: from the free market to knowledge capitalism", Journal of Education Policy, 20 (3): 313-345.

RIZVIA, Fazal; LINGARDB, Bob \& LAVIA, Jennifer (2006), "Postcolonialism and education: negotiating a contested terrain", Pedagogy, Culture \& Society, 14 (3): 249-262.

SANTOS, Boaventura de Sousa (2011), “A encruzilhada da Universidade Europeia”, Ensino Superior 41, Revista do SNESup, 1-8.

SANTOS, Boaventura de Sousa (2012) "The University at a Crossroads," Human Architecture: Journal of the Sociology of Self-Knowledge: 10(1): 7-16. Available at: http://scholarworks.umb.edu/ humanarchitecture/vol10/iss $1 / 3$

SUBEDIA, Binaya \& DAZA, Stephanie Lynn (2008), “The possibilities of postcolonial praxis in education", Race Ethnicity and Education, 11 (1): 1-10.

SPIVAK, Gayatri C. (1990), The Post-Colonial Critic: Interviews, Strategies, Dialogues. London: Routledge.

VEIGA, Amélia \& AMARAL, Alberto (2009), "Survey on the Implementation of the Bologna Process in Portugal”, Higher Education, 57(1): 57-69.

VEIGA, Amélia \& AMARAL, Alberto (2012), "Soft Law and the implementation problems of the Bologna process”, Educação, Sociedade \& Culturas, 36: 121-140.

VEIGA, Amélia; ROSA, Maria João \& AMARAL, Alberto (2006), “The internationalisation of Portuguese Higher Education: How are higher education institutions facing this new challenge?", Higher Education Management and Policy, 18(1): 105-120.

WODAK, Ruth (2002), “Aspects of Critical Discourse Analysis”, ZfAL 36: 5-31.

WODAK, Ruth (2011), "Complex Texts: Analysing, understanding, explaining and interpreting meanings", Discourse Studies, 13 (5): 623-633.

WODAK, Ruth \& FAIRCLOUGH (2010) "Recontextualizing European higher education policies: the cases of Austria and Romania", Critical Discourse Studies, 7(1): 19-40.

\section{RESUMOS}

A internacionalização do ensino superior é uma das forças motrizes das reformas da educação na União Europeia. A sua recontextualização e operacionalização nos vários países da Europa levanta uma série de questões sobre a qualidade académica, a justiça e a igualdade no ensino superior, exigindo um repensar crítico destes processos. Neste artigo sugere-se que os estudos pós-coloniais e descoloniais e as perspetivas de Wodak e Fairclough (2010) sobre recontextualização no âmbito da análise crítica de discurso podem constituir-se como recursos epistemológicos capazes de promover novas possibilidades de refl exão crítica, pesquisa e resistência no ensino superior, nomeadamente para o caso português.

The internationalization of higher education is one of the driving forces of contemporary education reforms in the European Union. Its recontextualization and operationalization in the various European countries poses a series of questions about academic quality, justice and equality in higher education, requiring a critical rethinking of these processes. This paper suggests that the postcolonial and decolonial studies as well as the proposals of Fairclough and Wodak (2010) on recontextualization within critical discourse analysis can serve as 
epistemological resources to promote new opportunities for critical reflection, research and resistance in higher education, with specific reference to Portugal.

L'internationalisation de l'enseignement supérieur est l'une des forces motrices de la réforme de l'éducation dans l'Union européenne. Sa recontextualisation et son opérationnalisation dans plusieurs pays d'Europe soulèvent un certain nombre de questions sur la qualité académique, la justice et l'égalité dans l'enseignement supérieur, ce qui nécessite une remise en question critique de ces processus. Cet article suggère que les études postcoloniales et dé-coloniales, ainsi que les perspectives de Fairclough et Wodak (2010) sur la recontextualisation dans le cadre de l'analyse critique du discours peuvent correspondre à des outils épistémologiques et promouvoir de nouvelles opportunités pour la réflexion critique, la recherche et la résistance dans l'enseignement supérieur, en particulier dans le cas portugais.

\section{ÍNDICE}

Palavras-chave: Internacionalização, ensino superior, estudos pós-coloniais, análise crítica de discurso, resistência.

Mots-clés: Internationalisation, enseignement supérieur, études postcoloniales, analyse critique du discours, résistance

Keywords: Internationalization, higher education, postcolonial studies, critical discourse analysis, resistance

\section{AUTOR}

\section{EUNICE SEIXAS}

Doutorada em Sociologia; Investigadora Integrada do CECS, ICS, Universidade do Minho euniceseixas@gmail.com 